\title{
Off-flavors monitoring in raw and treated water by means of an electronic tongue system
}

\author{
G.S.Braga ${ }^{1}$, L.G.Paterno ${ }^{2}$, F.J.Fonseca ${ }^{1}$ \\ ${ }^{1}$ Escola Politécnica da Universidade de São Paulo, CEP 05508-900, São Paulo-SP, Brazil. \\ gbraga@Ime.usp.br (G.S.Braga), fernando.fonseca@poli.usp.br (F.J.Fonseca) \\ ${ }^{2}$ Instituto de Química da Universidade de Brasília, Campus Universitário Darcy Ribeiro, CEP 70904- \\ 970 Asa Norte - Brasília-DF, Brazil
}

\begin{abstract}
:
An electronic tongue (ET) system based on non-specific chemical sensors was used to detect and quantify off-flavors compounds, namely geosmin (GSM) and 2-methylisoborneol (MIB), in raw and treated water samples collected from the Guarapiranga reservoir (Sao Paulo-Brazil). Four sets of samples were evaluated with the ET system: sets 1 and 2 were composed by raw and treated waters, respectively, and measured as collected whereas sets 3 and 4 were composed by raw and treated samples plus addition of known amounts of MIB and GSM. The electrical fingerprints (capacitance) generated by the ET for the different samples were processed by principal component analysis. The ET easily performed samples' discrimination while providing distinct and well-separated clusters for each type of sample. Furthermore, scores after repeated samples' replicas were close grouped which indicates that the ET's response is reproducible. The ET's sensitivity is also high and the presence of both GSM and MIB could be detected at concentrations as low as $20 \mathrm{ng} \cdot \mathrm{L}^{-1}$. The results confirmed the analysis performed independently by GC/MS spectrometry and by a human panel.
\end{abstract}

Key words: electronic tongue, off-flavors', geosmin, 2-methylisoborneol, water monitoring and impedance measurements.

\section{Introduction}

Detection and monitoring of off-flavors' compounds in potable water have been subject of different studies due to their relevance to environmental and health issues. Geosmin (GSM) and 2-methylisoborneol (MIB) have been recognized as the main species released during eutrophication. Their presence in water is readily recognized by their characteristic earthy-musty taste and odor [1]. Contamination of drinking water by MIB and GSM are the major source of complaints for water companies. They also affects aquaculture, because they give an unpleasant taste to fish $[2,3]$ and as well as to beverages such as grape juice [4] and wines [5]. Besides the unpleasant sensation, these compounds may also impose some threat to health. Therefore, their presence has to be monitored and controlled by highly sensitive instrumentation. Despite the extremely high sensitivity and accuracy of chromatographic methods, the actual demand for in locu and real time monitoring restricts their use and requires the development of miniaturized instrumentation.
The electronic tongue (ET) [6] can be a suitable choice to address such demands. Besides its lower cost and easier operation, the ET technology can provide faster response, more frequency sampling and, in addition can be implemented at remote locations. In our previous contributions, an ET system based on polymeric sensing units was successfully applied to detect GSM and MIB in artificially samples prepared with distilled and tap water, at concentrations as low as $25 \mathrm{ng} \cdot \mathrm{L}^{-1}$ [7]. The present contribution deals with the analysis of real water samples collected from a public water reservoir in Sao Paulo (Brazil). Part of these samples was analyzed as collected (in natura) while the other part (contaminated) was intentionally contaminated with known concentrations of MIB and GSM. The results provided by the ET were then compared with those attained with GC/MS spectrometry.

\section{Materials and Methods}

Water from the Guarapiranga reservoir

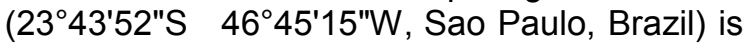
treated in water treatment plants (WTP) before being distributed for public consumption. Water 
samples were collected before (raw) and after (treated) the WTP. Four sets of water samples were analyzed with the ET system: sets 1 and 2 were respectively composed by raw (raw 1) and treated (treated 1) samples whereas sets 3 and 4 had the addition of known concentration of MIB and GSM. Samples were supplied by the São Paulo water and sewage company (SABESP). Raw sample 2 had an addition of MIB (60 ng. $\mathrm{L}^{-1}$ ) and GSM (50 ng. $\left.\mathrm{L}^{-1}\right)$. Treated sample 2 had an addition of MIB (30 ng. $\left.\mathrm{L}^{-1}\right)$ and GSM (20 ng. $\left.\mathrm{L}^{-1}\right)$. The concentration of MIB and GSM in the four samples was determined by CG/MS, as quoted in Table 1. Each sample set was divided in three aliquots to conduct the analysis by CG/MS; human panel, and by the ET system.

The ET system used is based on non-specific polymeric chemical sensors that are made of a gold interdigitated microelectrode coated with an ultra-thin polymeric film deposited via the layer-by-layer technique [8]. Polyaniline (PANI) and polyallylamine hydrochloride $(\mathrm{PAH})$, were used as polycations and polypyrrole (PPy), sodium sulfonated polystyrene (PSS), and sulfonated-lignin (SL). were used as polyanions. The film deposition was carried out with an automated system (Haubenteuer, V Company do Brasil), described previously [9]. Briefly, the deposition of the polymeric film was carried out by immersing the microeletrodes, alternatively, in the polycation and polyanion solutions $(\mathrm{pH} 2.7)$ for 3 minutes. Between each immersion, the microelectrode was immersed in a diluted $\mathrm{HCl}$ solution $(\mathrm{pH} 2.7)$ under stirring for cleaning. After immersing the microelectrode in the polycation and polyanion solution a bilayer was adsorbed. A total of 10 bilayers were deposited in each microelectrode used in the ET system. The array (electronic tongue) was composed by five sensors: a bare microelectrode-S1 and four types of polymeric sensors with ten polycation/polyanion bilayers; S2-PANI/PSS+PANI, S3-PAH/PPy; S4$\mathrm{PAH} / \mathrm{SL}$; S5-PANI/PSS. Sensor 02 had an extra (11th) layer of PANI.

The measurement system was composed by the ET connected to an impedance analyzer (Solartron SI 1260) through a multiplexer. The multiplexer acts as a switch and allows for interrogation of all sensors successively. Measurements and data acquisition were performed by the computer with the aid of a virtual instrument created in LabView. All measurements were acquired at a random sequence at $25^{\circ} \mathrm{C}$ with samples immersed in a thermostatic bath. The data generated by the sensor array (electrical capacitance response) were analyzed using principal component analysis (PCA), which is a statistical method used for the analysis of data matrices with multiple variables. Data matrices columns correspond to sensor's type and rows correspond to sensor's response to a water sample. For PCA, the computational routine was implemented in MatLab with the Statiscal Toolbox.

\section{Results and Discussion}

Table 1 collects the composition of raw and treated water samples as measured by GC/MS spectrometry. The concentration of MIB and GSM in samples kept as collected (raw-1 and treated-1) was inferior to $5 \mathrm{ng} \cdot \mathrm{L}^{-1}$. In artificially contaminated samples, their concentration slightly differed from values established in the preparation of the stock solutions.

Sensory analysis performed by the human panel considered several organoleptic parameters including bitterness, acidity, astringency, chlorine, irritating to the nostrils, etc. Raw water samples were analyzed just by smelling while treated water samples were also drunk. According to these analysis, sample treated 1 was classified as non-objectionable, e.g., proper to drink, while sample treated 2 was classified as objectionable, due to the strong earthy-musty odor besides the bitter taste. Raw water samples (raw 1 and 2, not treated) were classified as objectionable.

Tab. 1: Composition of raw and treated water samples collected from the Guarapiranga reservoir in terms of off-flavors' concentration. Concentrations determined by GC/MS spectrometry. Samples raw 1 and treated 1 were kept as collected (in natura). Samples raw 2 and treated 2 were artificially contaminated with MIB and GSM .

\begin{tabular}{|c|c|c|}
\hline Sample & {$[\mathrm{MIB}]\left(\mathrm{ng} . \mathrm{L}^{-1}\right)$} & {$[\mathrm{GEO}]\left(\mathrm{ng} \cdot \mathrm{L}^{-1}\right)$} \\
\hline Raw 1 & $<5.0$ & $<5.0$ \\
\hline Raw 2 & 61.0 & 34.0 \\
\hline Treated 1 & $<5.0$ & $<5.0$ \\
\hline Treated 2 & 25.0 & 19.0 \\
\hline
\end{tabular}

The electrical fingerprints provided by the ET for the different water samples were processed by PCA and the respective results are presented in the plot shown in Figure 1. It can be observed that the four samples were completely discriminated in the plot as they are grouped into four small and well-separated clusters with no overlapping. The ET discriminated them according to their main differences, e.g. matrix (raw or treated) and 
presence/absence of off-flavors. For example, scores referred to samples raw 1 and raw 2 are positioned exclusively in the third quadrant while scores of samples treated 1 and treated 2 are distributed between quadrants 1 and 2 , respectively. Furthermore, the presence of MIB and GSM in both types of samples was easily detected even when the matrix was of the same type. Additionally, the presence of off-flavors compounds was correlated with both PC's. As their concentration increases, the scores shift along PC 1, from left to right, or else along PC 2 , from bottom to top (in raw samples) or from top to bottom (in treated samples). Even more important, the ET presented a strong correlation with the human panel analysis. The ET distinguishes drinkable water (treated 1) from the rest of water samples (raw 1 and 2, plus treated 2) which were all considered undrinkable by the human panel. The results are very consistent and reliable as noted by the close grouping of scores acquired with samples' replicas. The lowest concentration detected by the ET of either MIB or GSM in treated water samples was about $20 \mathrm{ng} \cdot \mathrm{L}^{-1}$.

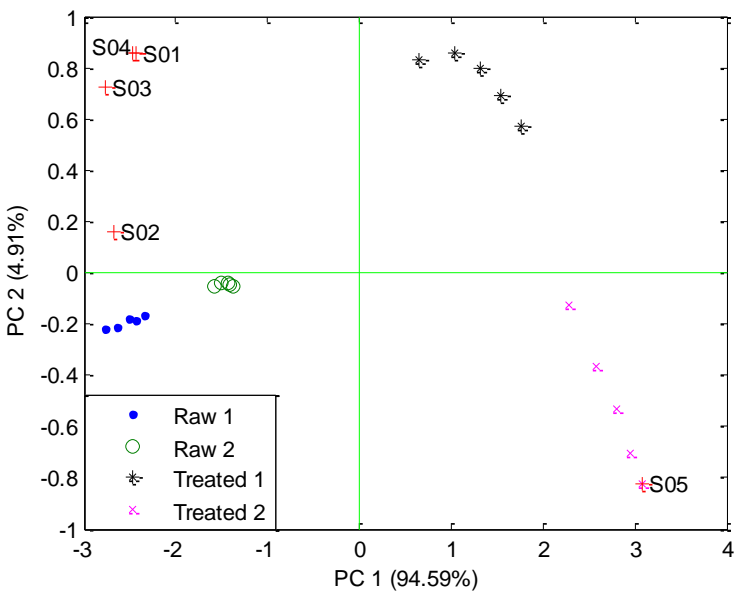

Fig. 1. PCA plot for raw and treated water samples analyzed by the ET system $\left(1 \mathrm{kHz}, 25^{\circ} \mathrm{C}\right)$. Samples composition are indicated in Table 1.

\section{Conclusions}

The electronic tongue system composed by polymeric sensors was capable to detect the presence of 2-methylisoborneol and geosmin in real water samples collected from the Guarapiranga reservoir (Sao Paulo, Brazil). The presence of these off-flavors was detected independently on the type of water (raw or treated). Moreover, the ET easily distinguished the drinkable water from the rest of undrinkable water samples, in the same manner as did the human panel analysis. The response of the ET system was very reliable and reproducible for five samples' replicas.
The results obtained so far are encouraging and point to a promising use of the present electronic tongue system for monitoring offflavors' compounds in water reservoirs.

\section{Acknowledgements}

The authors wish to thank FAPESP and $\mathrm{CNPq}$ for the financial support and SABESP for water sample supply and analysis.

\section{References}

[1] W.F. Young, et al.; Taste and odour threshold concentrations of potential potable water contaminants, Water Research 30 (1996) 331340; doi:10.1016/0043-1354(95)00173-5.

[2] P. Howgate; Tainting of farmed fish by geosmin and 2-methyl-iso-borneol: a review of sensory aspects and of uptake/depuration, Aquaculture 234 (2004) 155-181, doi:10.1016/j.aquaculture 2003.09.032.

[3] J.L. Smith, G.L. Boyer, P.V. Zimba; A review of cyanobacterial odorous and bioactive metabolites: Impacts and management alternatives in aquaculture, Aquaculture 280 (2008) 5-20; doi:10.1016/j.aquaculture 2008.05.007.

[4] H. Moralles-Valle, et al.; Microextraction and Gas Chromatography/Mass Spectrometry for improved analysis of geosmin and other fungal "off" volatiles in grape juice, Journal of Microbiological Methods 83 (2010) 48-52; doi:10.1016/j.mimet.2010.07.013.

[5] P. Darriet, M. Pons, S. Lamy, D. Dubourdieu; Identification and Quantification of Geosmin, an Earthy Odorant Contaminating Wines, J. Agric. Food Chem. 48 (2000) 4835-4838; doi:10.1021/jf0007683.

[6] N.K.L. Wiziack, et al.; Effect of film thickness and different electrode geometries on the performance of chemical sensors made of nanostructured conducting polymer films, Sens. and Actuators B: Chem 122 (2007) 484-492; doi:10.1016/j.snb.2006.06.016.

[7] G.S. Braga, et al., Performance of an electronic tongue during monitoring 2methylisoborneol and geosmin in water samples, Sens. Actuators B: Chem. (2012), doi:10.1016/j.snb.2012.02.092.

[8] G. Decher, Fuzzy Nanoassemblies: Toward Layered Polymeric Multicomposites, Science 277 (1997) 1232-1237; doi: 10.1126/science. 277.5330 .1232 .

[9] G.S. Braga, et al.; Influence of the deposition parameters on the morphology and electrical conductivity of PANI/PSS self-assembled films; Mat. Sci. and Eng. C 28 (2008) 555-562. 